\title{
Government Publications in the Classroom
}

$G$ OVERNMENT PUBLICATIONS are a most important form of library material. In many subjects they are a rich and fundamental source of information which cannot be neglected, especially by students in history, political science, and sociology. Many publications are transcripts of original records and constitute primary source materials in the history of government administration. Others, such as annual reports, contain accounts by executive officers of the work of their offices. Numerous series published by various agencies and departments provide statistics for measuring social and economic changes. For the most part, they are free or inexpensive.

The value of government publications is matched, however, by the diffculty of using them. The average student usually hesitates to consult them because out of the great mass of material he does not understand how to locate what he needs. (And this is equally true of many faculty members.) For example, a student in political science who lives in Georgia's Fifth Congressional District was asked to find out the bills introduced in Congress by his representative. After these had been listed, he was asked to take one of the bills and follow each step of legislation. A recent class assignment asked for the United States diplomatic representatives in the NATO countries and their representatives to the United States. All of this information may be found in government publications, but assistance and explanations about their contents and location is needed, since the peculiari-

Mr. Estes is Reference Librarian, Emory University Library. ties of their organization, bibliography and indexing are baffling to the uninitiated. It is necessary, therefore, to make them available and to provide instruction in their use. Since all librarians are uneasily aware of these things, an account of what is being done by the Emory University Library to promote government documents and give instruction in their use, even though it is a limited program, may be of interest.

The library is a partial depository for the official publications of the United States Government. There is a documents center, where most of these publications are housed and where reference service is provided to assist students and faculty in their use. Here the bibliographic aids are assembled on one range of shelving, not only Poore, Ames, the Documents Index, the Documents Catalog and the Monthly Catalog, but also lists of publications, bibliographies and indexes issued by individual government agencies. These serve as a checklist of Emory's holdings and give the classification numbers by which the documents are arranged.

Two "self-help" guides have been prepared by the reference department. One, "The Documents Center: Finding and Using Government Publications," describes the types of documents and explains the procedure for identifying a specific document as well as the arrangement, location and classification of the collection. The other, "U. S. Government Publications in the Emory University Library Which Contain Material on Congressional Bills," is a mimeographed guide giving brief definitions of all types of bills and resolutions. It gives information on the printing, distribution and 
indexing of bills, resolutions and reports of committees of Congress and also provides information and direction for using the Congressional Record, the Digest of Public General Bills, and tells how to trace a bill.

Group instruction in the use of documents is also given. Special arrangement is made for students in political science who study American government-its history, functions and procedures. In order that these students might better understand the workings of the government, the author and the staff of the political science department decided to introduce federal documents in the introductory course on American government. For the past five years lectures have been given to students in these classes. The remainder of this paper is concerned with a description of these lectures.

Government publications can be divided into three groups corresponding to the three branches of the government: congressional or legislative publications -those relating to the proceedings of Congress; judicial publications-court decisions, etc.; and executive publications-those published by the executive departments and independent agencies. The library's treatment and arrangement of these publications is described first. Then some of the more outstanding documents and their relation to the program of the class are studied. Copies of the publications to be discussed are brought to class.

A class lecture on United States government publications may be given for a one-hour period or for two periods of one hour each, according to the wishes of the instructor. If only one hour is devoted to the lecture, most of the time is given to the congressional publications. Due consideration is given to the Congressional Directory, a copy of which is taken to the class to give students an idea of what it looks like and the type of information it contains-biograph- ical material on senators and representatives, committee assignments, terms of service, party leaders, etc. A student will often ask questions about his senator or representative.

The next step covers bills of each house. An example of each kind of bill and resolution is carried to the class for students to examine. One bill from either house is briefly traced and publications covering each phase of passage are shown and discussed. Each printing of the bill, whether one or a dozen or more, is taken to class. Amendments, readings, printings, etc., are brought out and the change from bill to act is noted. Information on the bill as to number, date introduced, and by whom, is read. If the bill chosen for example is a Senate bill, and Senate hearings are held, a copy of the printed hearings is shown along with an explanation of the difference between a hearing and a committee report. The list of people appearing before the committee is covered in order to point out the number and types of people present. The committee report is also shown with the explanation that this is the committee's opinion on the bill. If the bill goes to the House and hearings are held, these as well as the House report are shown.

The Congressional Record and its index are then covered. A daily issue of the Record, a fortnightly index, and a copy of the bound index are exhibited with explanations given about the use of each. A copy of the bound index is used since legislation already bound is usually discussed. Explanations for using the three sections of the index are given. Special attention is focused on a member of Congress, the bills he introduced, and the remarks he made. Students are sometimes asked to find how a particular senator voted on the passage of a bill.

If the bill has become a law, a copy of the slip law is shown, the title being read as well as the number of the bill 
responsible for the law. Except for the initial printing in slip bill form, a bill is not reprinted in its entirety elsewhere. It is necessary therefore for a library to preserve the bills of both houses, if a person doing research on a bill needs to read the original bill as introduced.

A brief discussion is given on the Digest of Public General Bills, which is prepared by the Legislative Reference Service of the Library of Congress. This publication presents the bill in simple form and reports action which has been taken on it. The latest copy is shown and its location in the library is noted. It is well to explain here that this is most helpful to those students doing more research on a bill or perhaps to those who plan to major in political science. House and Senate journals are also discussed. They appear at the end of each session of Congress and contain all motions, roll-call votes and various other matters such as the President's message to Congress, but no debates. A list of bills introduced in both houses by number and title is provided in each journal.

From time to time there are questions from the class about the publications which are being discussed or perhaps requests for a recapitulation of a particular phase of the lecture. These are always welcomed as they pin-point sparks of interest as well as keep the instructor alert to how well the lecture is being received. At the end of the hour the class is given a group of questions which will require their visiting the library to answer. These include having the student name the representatives from his state and the number of the district he represents, asking for the names of chairmen of certain committees, or perhaps the name of the committees certain congressmen serve on. After all questions are answered they are turned in to the instructor and, if possible, he gets together with the lecturer for an evaluation of the class period.

If a second lecture is given, the executive and judicial branches are covered in the same manner. The United States Government Organization Manual is taken to class and all types of information in it are noted. Each department, along with its branches and offices and their publications, is discussed. Mention is made of outstanding independent agencies, such as the United States Civil Service Commission, The Smithsonian Institution, and the Library of Congress.

Because of this class instruction bibliographic aids for the United States government documents have been given much wider use in the Emory Library. Students recognize the importance and value of such publications as the Congressional Directory, the Congressional Record and the United States Government Organization Manual. Faculty members have noticed more interest in the work of Congress and the executive departments on the part of students, and many students state that discussing the actual documents has clarified the work for them. With this program, the Emory Library is participating actively in the educational process and demonstrating its basic importance in the life of the university.

This воок is DEDicated to those devoted public servants, the librarians and archivists who keep, preserve, and make available the manuscripts and printed material which are the living record of our past.-Dedication in Philip Van Doren Stern's An End to Valor (Boston, 1958). 